\title{
DONOR/ACCEPTOR SUBSTITUTED OLIGOTHIOPHENES: SYNTHESIS, SPECTROSCOPIC AND ELECTROCHEMICAL PROPERTIES
}

\author{
M. Manuela M. Raposo ${ }^{*}$, A. Maurício C. Fonseca ${ }^{1}$ and G. Kirsch ${ }^{2}$ \\ 1 Centro de Química, Universidade do Minho, Campus de Gualtar, 4710-057, Braga, Portugal. \\ 2 Laboratoire d'Ingénierie Moléculaire et Biochimie Pharmacologique, Faculté de Sciences, \\ Université de Metz, 57012 Metz, France.
}

Keywords: Stille coupling, chromophores, donor/acceptor oligothiophenes, UV-visible spectroscopy, electrochemistry, non-linear optical material (NLO).

\begin{abstract}
Seven new donor/acceptor oligothiophenes 1-2 were synthesized by Stille coupling in moderate to good yields. Compounds 1-2 were completely characterized by the usual spectroscopic methods. In agreement with the electrochemical and the spectroscopic studies for this compounds the new derivatives prepared, can find application for manufacturing new materials with strong non-linear optical (NLO) properties.
\end{abstract}

\section{Introduction}

In the past few years interest has been focused on new organic materials with non-linear optical properties [1,2], and it was proved that, introduction of the thiophene nucleus enhance these properties [3,4]. Thiophenes and oligothiophenes substituted by donor/acceptor groups have been extensively investigated. These compounds are often used as energy transfer and light-harvesting systems and for optical and electronic devices [4-7]. Unsymetrically substituted oligothiophenes are usually synthesised by cross-coupling reactions; Stille, Suzuki, or others and by procedures involving thiophene ring formations [8]. As part of our continuing interest in non-linear optical material [9-12] we have synthesised several new donor/acceptor oligothiophenes 1-2, by Stille coupling, using as precursors the 5-amino-2,2'-bithiophenes described by us recently [13].

\section{Results and discussion}

\section{Synthesis}

Our recent reported synthesis of 5-alkoxy- and 5-amino-2,2'-bithiophenes made these compounds available in reasonable amounts, ready for further applications. Indeed we were able to use this compounds with sucess as substrates for the Stille coupling [14]. The stannane derivative 3, easily prepared from 5-piperidino-2,2'-bithiophene 4 was coupled with the appropriate phenyl, thienyl and bithienyl bromides 5-7 (Fig. 1) to give the title compounds 1-2 (Scheme 1).

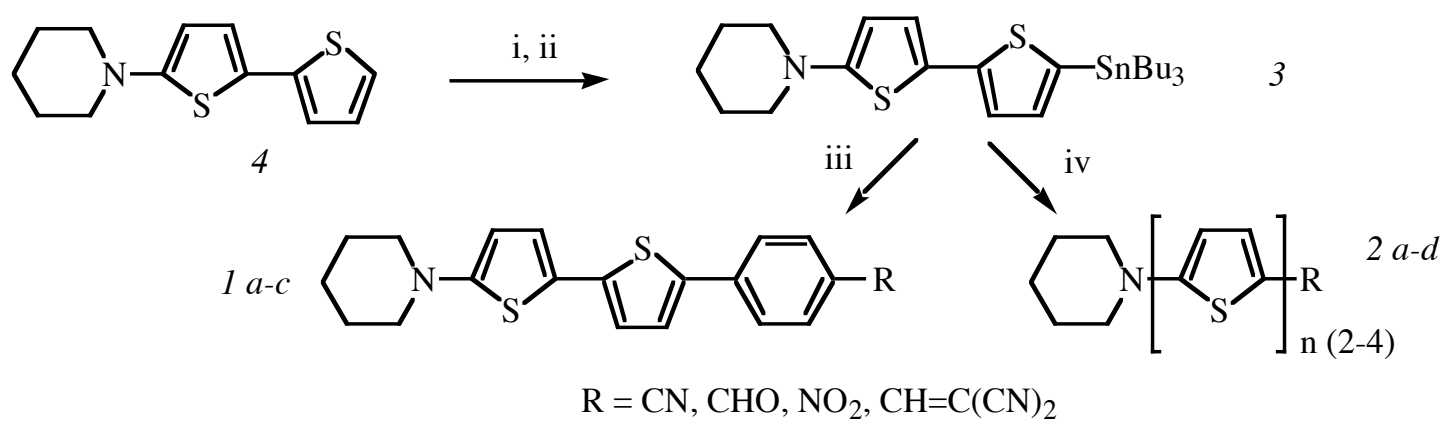

Reagents and conditions; i, $n$-BuLi, dry ether, $0{ }^{\circ} \mathrm{C}$, Ar; ii, $\mathrm{CH}_{3}\left(\mathrm{CH}_{2}\right)_{3} \mathrm{SnCl}$, dry ether, $-70{ }^{\circ} \mathrm{C}$, Ar; iii, 5, $\mathrm{Pd}\left(\mathrm{PPh}_{3}\right)_{4}$, toluene, $80{ }^{\circ} \mathrm{C}$, $\mathrm{Ar}$; iv, 6 or $7, \mathrm{Pd}\left(\mathrm{PPh}_{3}\right)_{4}$, toluene, $80{ }^{\circ} \mathrm{C}, \mathrm{Ar}$.

Scheme 1- Synthesis of donor/acceptor oligothiophenes 1-2 by Stille coupling. 

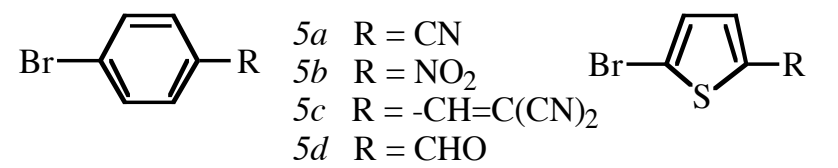

$\begin{array}{ll}6 a & \mathrm{R}=\mathrm{CHO} \\ 6 b & \mathrm{R}=\mathrm{NO}_{2} \\ 6 c & \mathrm{R}=-\mathrm{CH}=\mathrm{C}(\mathrm{CN})_{2}\end{array}$<smiles>N#CC(C#N)=Cc1ccc(-c2ccc(Br)s2)s1</smiles>

Figure 1- Structure of phenyl, thienyl and bithienyl bromides 5-7.

A series of chromophores was synthesized with piperidino donnor group and formyl, nitro and dicyanovinyl acceptors across a conjugated $\pi$-bridge containing a bithiophene-benzene, terthiophene or tetrathiophene moieties.

The bithiophenes $l a-c$, the terthiophenes $2 a-c$ and the tetrathiophene $2 d$ were synthesised by $\mathrm{Pd}\left(\mathrm{PPh}_{3}\right)_{4}$ catalyzed cross coupling reaction of (tributhylstannyl)bithiophene 3 with the acceptorsubstituted bromo aryl or heteroaryl compounds 5,6 or 7 . Bromides $5 a-b, 5 d$ and $6 a$ were commercial availables. The synthesis of the other bromo derivatives was achieved by several methods. Knoevenagel condensation of the commercial available $5 d$ and $6 a$ with malononitrile in refluxing ethanol gave the corresponding dicyanovinyl derivatives $5 c$ and $6 c$ in 87 and $91 \%$ yield respectively. 2-Bromo-5'-dicyanovinyl-2,2'-bithiophene 7 was obtained from 5-dicyanovinyl-2,2'bithiophene by bromination with NBS in a solution of chloroform-acetic acid (1:1) in $85 \%$ yield. 5Dicyanovinyl-2,2'-bithiophene was obtained in 55\% yield, by Stille coupling of (tributhylstannyl)thiophene with derivative $6 c$ under $\mathrm{Pd}\left(\mathrm{PPh}_{3}\right)_{4}$ catalysis at $80{ }^{\circ} \mathrm{C}$ in toluene. (Tributhylstannyl)thiophene was synthesized from the commercial available 2-bromothiophene by lithiation, using $n$ - $\mathrm{BuLi}$ at $0{ }^{\circ} \mathrm{C}$, followed by transmetalation with tributhyltin chloride at $-78{ }^{\circ} \mathrm{C}$ in quantitative yield. The bromo derivatives $5 c, 6 c$ and 7 described early were synthesized in order to be coupled under Stille conditions with the stannane bithiophene 3. The synthesis of bithienylstannane 3 were achieved by metalation of 5-piperidino-2,2'-bithiophene 4 , using $n$-BuLi at $0^{\circ} \mathrm{C}$ followed by quenching with tributhyltin chloride at $-78^{\circ} \mathrm{C}$ in $83 \%$ yield.

The Stille reactions were performed in toluene under an argon atmosphere and $\mathrm{Pd}\left(\mathrm{PPh}_{3}\right)_{4}(2 \mathrm{~mol} \%)$ was used as palladium catalyst at $80{ }^{\circ} \mathrm{C}$ for $8-33.5 \mathrm{~h}$ (Scheme 1). The donor-acceptor oligothiophenes 1-2 were obtained in moderate to good yields (42-55\%) (Table 1).

Table 1- Yields and UV-Vis spectra data of compounds 1-2.

\begin{tabular}{|c|c|c|c|c|c|}
\hline Bromide & $R$ & Product & $\begin{array}{l}\text { Reaction } \\
\text { time }[\mathrm{h}]\end{array}$ & $\begin{array}{c}\text { Yield } \\
{[\%]} \\
\end{array}$ & $\lambda_{\max }[n m](\varepsilon)$ \\
\hline $5 a$ & $\mathrm{CN}$ & Piperidino-T2-4-CN-Ph $1 a$ & 19 & 43 & $420.0(18660)$ \\
\hline $5 b$ & $\mathrm{NO}_{2}$ & Piperidino- $\mathrm{T}_{2}-4-\mathrm{NO}_{2}-\mathrm{Ph} \mathrm{lb}$ & 8 & 53 & $449.0(10000)$ \\
\hline $5 c$ & $-\mathrm{CH}=\mathrm{C}(\mathrm{CN})_{2}$ & $\begin{array}{c}\text { Piperidino- } \mathrm{T}_{2}-4-\left[\mathrm{CH}=\mathrm{C}(\mathrm{CN})_{2}\right]-\mathrm{Ph} \\
1 c\end{array}$ & 30 & 42 & $384.0(45960)^{1}$ \\
\hline $6 a$ & $\mathrm{CHO}$ & Piperidino-T3-CHO $2 a$ & 17 & 51 & $455.0(15260)$ \\
\hline $6 b$ & $\mathrm{NO}_{2}$ & Piperidino- $\mathrm{T}_{3}-\mathrm{NO}_{2} 2 b$ & 33 & 53 & $504.0(10100)$ \\
\hline $6 c$ & $-\mathrm{CH}=\mathrm{C}(\mathrm{CN})_{2}$ & Piperidino- $\mathrm{T}_{3}-\left[\mathrm{CH}=\mathrm{C}(\mathrm{CN})_{2}\right] 2 c$ & 33.5 & 55 & $544(22000)$ \\
\hline 7 & $-\mathrm{CH}=\mathrm{C}(\mathrm{CN})_{2}$ & Piperidino- $\mathrm{T}_{4}-\left[\mathrm{CH}=\mathrm{C}(\mathrm{CN})_{2}\right] 2 d$ & 30 & 45 & $461.0(22438)^{1}$ \\
\hline
\end{tabular}

1 All the UV/Vis. spectra were run in ethanol except for $1 c$ and $2 d$ where acetonitrile was used. 


\section{UV-visible study}

Electronic absorption spectra of all the push-pull compounds 1-2 demonstrate an intense lowest energy charge-transfer absorption band in the UV-vis. region. The energy of this lowest absorption band reflects the charge-transfer properties of these compounds, and is a function of the donor and acceptor strengths as well as the lenght and effectiveness of conjugation (Table 1). The influence of the strength of the acceptor group is demonstrated by comparison of the absorption maxima of compounds $2 a$ and $2 c$ : the longest wavelength transition is shifted from $455 \mathrm{~nm}$ in piperidino- ${ }_{3}-$ CHO $2 a$ to $544 \mathrm{~nm}$ in piperidino- $\mathrm{T}_{3}-\left[\mathrm{CH}=\mathrm{C}(\mathrm{CN})_{2}\right] 2 c$. Comparison of the electronic absorption spectra of piperidino- $\mathrm{T}_{2}-4-\mathrm{NO}_{2}-\mathrm{Ph} 1 b\left(\lambda_{\max }=449 \mathrm{~nm}\right)$ with piperidino- $\mathrm{T}_{3}-\mathrm{NO}_{2} 2 b\left(\lambda_{\max }=504\right.$ $\mathrm{nm})$ reveals that the replacement of a benzene ring with a thiophene ring causes a dramatic red shift of the charge-transfer band. This observation clearly indicates that the incorporation of thiophene moieties in push-pull compounds enhances their charge-transfer properties.

\section{Electrochemistry}

To get a deeper insight into the ground state properties and more specifically the mutual donoracceptor electronic influence, we studied the redox properties of compounds 1-2 by cyclic voltammetry and the results are presented in Table 2.

Table 2- Electrochemical data for oligothiophenes 1-2.

\begin{tabular}{|c|c|c|c|c|}
\hline \multirow[t]{2}{*}{ Compound } & \multirow{2}{*}{$\begin{array}{c}\text { Reduction }^{a} \\
-\mathrm{E}_{1 / 2}[\mathrm{~V}]\end{array}$} & \multicolumn{3}{|c|}{ Oxidation $^{a}$} \\
\hline & & $\begin{array}{c}{ }^{1} \mathrm{E}_{1 / 2} \\
{[\mathrm{~V}]} \\
\end{array}$ & $\begin{array}{c}\Delta^{1} \mathrm{E}_{1 / 2} \\
{[\mathrm{mV}]}\end{array}$ & $\begin{array}{c}{ }^{2} \mathrm{E}_{1 / 2} \\
{[\mathrm{~V}]} \\
\end{array}$ \\
\hline Piperidino- $\mathrm{T}_{2}-4-\mathrm{CN}-\mathrm{Ph} 1 a$ & 1.64 & 0.16 & 106 & 0.38 \\
\hline Piperidino- $\mathrm{T}_{2}-4-\mathrm{NO}_{2}-\mathrm{Ph} \quad 1 b$ & 1.43 & 0.19 & 112 & 0.40 \\
\hline Piperidino- $\mathrm{T}_{2}-4-\left[\mathrm{CH}=\mathrm{C}(\mathrm{CN})_{2}\right]-\mathrm{Ph}$ & 1.32 & 0.05 & 106 & 0.33 \\
\hline $1 c$ & & & & \\
\hline Piperidino- $\mathrm{T}_{3}-\mathrm{CHO} 2 a$ & 1.59 & 0.04 & 122 & 0.26 \\
\hline Piperidino- $\mathrm{T}_{3}-\mathrm{NO}_{2} 2 b$ & 1.36 & 0.08 & 136 & 0.32 \\
\hline Piperidino- $\mathrm{T}_{3}-\left[\mathrm{CH}=\mathrm{C}(\mathrm{CN})_{2}\right] 2 c$ & 1.29 & 0.14 & 144 & 0.41 \\
\hline Piperidino- $\mathrm{T}_{4}-\left[\mathrm{CH}=\mathrm{C}(\mathrm{CN})_{2}\right] 2 d$ & 1.31 & 0.07 & 95 & 0.42 \\
\hline
\end{tabular}

$a \overline{\text { Measurements made in acetonitrile containing 0.1-0.2 } \mathrm{mol} \mathrm{dm}^{-3}\left[\mathrm{NBu}_{4}\right]\left[\mathrm{BF}_{4}\right] \text { as base }}$ electrolyte at a carbon working electrode with a scan rate of $0.1 \mathrm{~V} \mathrm{~s}^{-1}$. Ferrocene was added as an internal standard at the end of each measurement, and all $E_{1 / 2}$ values are quoted in volts $v s$ the ferrocene-ferrocenium couple.

All the voltammograms show the presence of two reversible one-electron oxidation waves, corresponding to the formation of the cation radical and dication. Communication between the electron donating and accepting termini can be evaluated by comparing the $\mathrm{E}_{1 / 2}$ values. A more positive half wave potential suggests that the unit is more difficult to oxidize (i.e. less electron rich). The differences in $\mathrm{E}_{1 / 2}$ potentials between the compounds piperidino- $\mathrm{T}_{3}-\left[\mathrm{CH}=\mathrm{C}(\mathrm{CN})_{2}\right] 2 c$, piperidino- $\mathrm{T}_{3}-\mathrm{NO}_{2} 2 b$ and piperidino- $\mathrm{T}_{3}-\mathrm{CHO} 2 a$, demonstrate the influence of the acceptor group on the oxidation potentials. The introduction of a $4^{\text {th }}$ thiophene ring in the $\pi$ bridge in the case of piperidino- $\mathrm{T}_{4}-\left[\mathrm{CH}=\mathrm{C}(\mathrm{CN})_{2}\right] 2 d\left({ }^{1} \mathrm{E}_{1 / 2}=0.07 \mathrm{~V}\right)$ result in an increase negative shift of the first oxidation potential: piperidino- $\mathrm{T}_{3}-\left[\mathrm{CH}=\mathrm{C}(\mathrm{CN})_{2}\right] 2 c\left({ }^{1} \mathrm{E}_{1 / 2}=0.14 \mathrm{~V}\right)$. Moreover, comparison of 
oxidation potentials of piperidino- $\mathrm{T}_{3}-\mathrm{NO}_{2} 2 b\left({ }^{1} \mathrm{E}_{1 / 2}=0.08 \mathrm{~V}\right)$ with piperidino- $\mathrm{T}_{2}-4-\mathrm{NO}_{2}-\mathrm{Ph} 1 b$ $\left({ }^{1} \mathrm{E}_{1 / 2}=0.16\right)$ showed dependence on the type of the bridge. The electrochemical results shows there is a large intramolecular charge delocalization in compounds 1-2 (Table 2). In fact, it is this charge transfer which is responsible for the nonlinear optical response in non-linear optical materials [15].

In contrast, the reduction of the series occurs in an irreversible one-electron reduction. The data illustrate that there is quite an obvious electrochemical distinction between the compounds depending on the type of $\pi$-bridge, bridge length and the type of donor and acceptor groups, (Table 2 ). Thus increase of capacity of the acceptor group or of the capacity of the donor group results in a decrease negative shift of the reduction potential $E_{1 / 2}$. The differences in the $E_{1 / 2}$ potentials between the terthiophene, tetrathiophene and 5'-phenyl-2,2'-bithiophene moieties with donor/acceptor similar groups demonstrates the influence of the $\pi$-bridge on the reduction potential. The trends observed for the redox potentials and $\lambda_{\max }$ of the oligothiophene derivatives are dependent on the acceptor group and on the conjugated bridges. The dicyanovinyl is a more effective electron acceptor group than nitro or formyl group. Comparison of electrochemical data for the piperidino- $\mathrm{T}_{3}-\mathrm{NO}_{2} 2 b$ with the corresponding piperidino- $\mathrm{T}_{2}-4-\mathrm{NO}_{2}-\mathrm{Ph} 1 b$ reveals that the terthiophene bridge provides a more efficient delocalization pathway than $5^{\prime}$-phenyl-2,2'bithiophene moiety. The large potential difference between the two oxidation processes suggests that there is a good electronic communication between the donor/acceptor end groups for the compounds studied.

\section{Conclusions}

The Stille coupling of the bromo derivatives 5-7 with the stannylbithiophene 3 under $\operatorname{Pd}\left(\mathrm{PPh}_{3}\right)_{4}$ catalysis yielded the new donor- $\pi$-acceptor systems $1-2$ in moderate to good yields. These derivatives were completely characterised by HRMS, and IR, UV-vis. and ${ }^{1} \mathrm{H}$ NMR spectroscopic techniques. In agreement with the electrochemical and the spectroscopic studies of compounds $1-2$ and also with previous findings [15-17], the new compounds prepared, can find application for manufacturing new materials with strong non-linear optical (NLO) properties. Studies of NLO properties of these compounds are under investigation.

\section{References}

[1] P.N. Prasad and D.J. Williams, Introduction to non-linear effects in molecules and polymers (Wiley, New York 1991).

[2] C. Brosshard, K. Sutter, P. Petre, J. Hulliger, M. Florsheimer, M. Kaatz, and P. Gunter, Organic non-linear optical materials (Gordon and Breach Science Publishers, Amsterdam 1995).

[3] M.G. Hutchins, I. Ferguson, D.J. McGeein, J.O. Morley, J. Ziss, and I. Ledoux, J. Chem. Soc., Perkin Trans. 2, 175, (1995).

[4] F. Wuerthner and F. Effenberger, Chem. Phys. 173, (1993), 305.

[5] F. Steybe, F. Effenberger, S. Beckman, P. Kramer, C. Glania, and R. Wortmann, Chem. Phys., 219, (1997), 317.

[6] F. Steybe, F. Effenberger, S. Beckman, U. Gluber, C. Bosshard, and P. Gunter, Tetrahedron $54,(1998), 8469$.

[7] H.A.M. Van Mullekom, J.A.J.M. Vekemans, E.E. Havinga and E.W. Meijer; Materials Science and Engineering 32, (2001), 1.

[8] P. Bauerle In: The Synthesis of Oligothiophenes, D. Fichou Ed. Handbook of Oligo- and Polythiophenes (Wiley-VCH, Weinheim 1999), Cap. 3, p 89-173.

[9] D. Prim and G. Kirsch, J. Chem. Soc., Perkin Trans. 1 (1994), 2603.

[10] D. Prim, G. Kirsch, F. Leising, and G. Mignani, J. Heterocycl. Chem. 31, (1994), 1005.

[11] D. Prim, D. Joseph and G. Kirsch, Phosphorus, Sulfur and Silicon 91, (1994), 137.

[12] S.P.G. Costa, J. Griffiths, G. Kirsch and A.M.F. Oliveira-Campos, Anales de Quimica Int. Ed. 94, (1998), 186.

[13] M. Manuela M. Raposo and G. Kirsch , Heterocycles 55 (8), (2001), 1487.

[14] J.K. Stille, Angew. Chem. Int. Ed. Engl. 25, (1986), 508.

[15] F. Effenberger, F. Wuerthner, and F. Steybe, J. Org. Chem. 60, (1995), 2082.

[16] K. Eckert, A. Schroder and H. Hartmann, Eur. J. Org. Chem. (2000), 1327. 
[17] K-Y. A. Jen, V.P. Rao, K.J. Drost, Y. Cai, R.M. Mininni, J.T. Kenney, E.S. Binkley and L.R. Dalton, Proc. SPIE-Int. Soc. Opt. Eng. (1994), 2285; (Chem. Abstr., 123, 1995, 84708f).

\section{Acknowledgements}

Thanks are due to FCT for finantial support through IBQF (UM), and POCTI (ref. POCTI/QUI/37816/2001). 